\title{
Editorial: Diabetes resilience? Is it important?
}

Indonesian Nursing Journal of Education and Clinic (INJEC)

Volume 4, Issue 2, December 2019 injec.aipni-ainec.org/index.php/INJEC/index The Association of Indonesian Nurse Education Center (AINEC)

https://injec.aipniainec.org/index.php/INJEC/issue/view/I6/show Toc

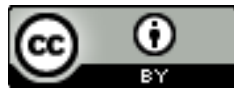

Hidayat Arifin, S. Kep., Ns. M. Kep.

Faculty of Nursing, Universitas Airlangga, Surabaya, Indonesia

email: hidayat.arifin@staf.unair.ac.id

Diabetes is a chronic disease characterized by increased blood sugar levels in the body which can cause various complications if not controlled. Stress conditions can make people with diabetes mellitus in a worse condition. Diabetes therapy, which includes diet, activity, medication, and stress management which must be done every day, can cause burnout which leads to failure of diabetes mellitus management. This can lead to a worse condition characterized by increased blood sugar levels, foot ulcers, and other complications. Resilience defined as the development, ability, or outcome of successful adaptation in spite of challenging or threatening conditions. Diabetes resilience is defined as achievement of one or more positive diabetes outcomes (i.e., high engagement in diabetes self- management behaviours, self-perception of having good Quality of Life (QoL), withintarget glycemic outcomes) despite the challenges of living with type 2 diabetes. Patients T2DM with resilience disorder will be caused negative adaptation on treatment. This can lead to a decrease in the ability to take care of themselves, such as the ability to seek treatment, activity, and diet. Adult personal resilience that explained by (Taormina, 20I5), which includes I) determination, building determination becomes the basis of someone to become resilience. Participants must have the intention and determination to be able to succeed and survive undergoing type 2 diabetes mellitus which is fluctuating and long-lasting. This component also reflects the conscious dimension or cognitive ability of participants to survive. 2) After the participants have a good and strong determination, participants must have good endurance. It is intended for participants to survive in pleasant and unpleasant situations. This can occur in cognitive and physical condition. 3) Adaptability is defined as the capacity to be flexible and resourceful and to cope with adverse environments and adjust oneself to fit into changing conditions. This aspect is more cognitive than physical because one can make a conscious effort to improve participants thinking and behavior. Participants can adapt and accept the terms being experienced more easily. Good adaptability will help participants to become more resilient. 4) Recuperability is defined as the ability to recover, physically and cognitively, from various types of harm, setbacks, or difficulties to return and reestablish the condition. At this stage, participants can understand and understand the requirements experienced. Participants can do the recuperability independently to achieve good self-care. 